\title{
Current Status of Health Reporting in Nepali Press
}

Sabita Tuladhar, Khem Raj Shrestha, Nimesh Regmi, Ashoke Shrestha, Bharat Ban

With the introduction of the New Communication Policy 1992, the number of both electronic and print media has increased in Nepal. The print among other media is important because of its ability to present news and views in detail, thus stimulating individual's level of understanding. As in other fields, the importance of newspapers in health is also significant, suggesting need of research on the quality and the quantity of health reporting in the Nepali press.

The Health News Clipping Project studied 11 dailies and 7 weeklies for 28 months, to understand the range of healthrelated topics covered in the press. Out of 5,968 health news stories captured by the project, the contribution of the Gorkhapatra, the Kantipur and the Annapurna Post was prominent. More than $90 \%$ of the reporting was news stories and $83 \%$ of these stories' placement was in inside pages, and mostly these stories covered national issues. The project tracked 42 health related key words in the reporting where health facility, health worker, ministry of health and population, district public health offices, and drug supply were ranked the top five issues. Content analysis of sample coverage revealed that the main portion of reporting was about communicable diseases, health system, service delivery, and governance issues.

Eventhough health journalism in Nepal has a long history, any empirical research has yet to be conducted. Monitoring of health reporting in print media is an important aspect of quality improvement of the health reporting as well as increasing awareness on health to people. It is suggested that the Project could be a role model for the Ministry of Health and Population

(C) 2013 Kathmandu University, Nepal. http://www.ku.edu.np/bodhi 
for implementation of effective monitoring mechanism for the enhancement of the health related reporting in Nepal.

\section{The Context}

Media institutions have flourished in Nepal in their size and number after the introduction of the New National Communication Policy 1992, which promoted the development of private print and broadcast media. ${ }^{i}$ This policy led to media freedom, and at present government sources claim that $476 \mathrm{FM}$ radio stations, 35 television stations, 298 newspaper dailies and 1,442 weekly newspapers were registered in the country before 2012. This figure shows that there is greater demand among population for accurate, relevant, and impartial information dissemination institution, and the mass media such as radio, television and newspapers are still considered very effective communication medium in reaching information to people in a large scale. Media scholars argue that media have power to attract public attention towards the matter of their interest. ${ }^{\text {ii }}$ Mass media is successful not only in telling their readers what to think, but also are successful in broadening areas of such thinking. ${ }^{\text {iii }}$ In Nepalese context too, where access to electronic media, particularly television, has limited reach, the expansion of print media remains important.

Newspapers are a major source of information, opinion and analysis, which impart knowledge, influence the understanding of issues by their readers and advocate for the recipients of news items. ${ }^{\text {iv }}$ Government sources show that print media like newspapers have become major sources of information to the public. About 34 percent of men and 13 percent of women read newspapers at least once a week. ${ }^{\mathrm{V}}$ In the future the number of newspaper readers might increase because nearly half of the households in Nepal still do not have electronic media, particularly the television; those who have these facilities are also facing power shortage. Similarly, various sources indicate that literacy rate of the people is going up for a couple of years and it could be interpreted that there is increasing readership 
and the trend could continue further. These are some consequences which indicate that newspapers will be very crucial sources of information on different areas including health. The relative importance of newspapers among other media is greater because it has ability to present news and views in detail, thus, stimulating individuals' level of understanding, response and subsequent effects on the subject matter.

\section{The Issue}

Studies on health reporting in newspapers in Nepal or elsewhere are limited. The available literatures show that governments are increasing subsidies for improvement of health coverage in media, particularly to the newspapers because of their greater potency to affect the society's mainstream. The public rely upon the news media for information and policy makers also obtain considerable amount of information from the media. ${ }^{\mathrm{vi}}$ Thus, the importance of health reporting in newspapers in Nepal is high but due to lack of studies, the area appears undervalued. Few organizations in Nepal have attempted to analyze health coverage on selected topics such as HIV/AIDS, early marriage and early pregnancy. ${ }^{\text {vii }}$ Though these studies provide a snapshot of what is being published in selected areas of health, they lack comprehensiveness in presenting the complete picture of health reporting in newspapers in Nepal.

The challenges and constraints faced by health newspaper journalists are yet to be researched. It is often commented that media, particularly newspapers in Nepal have a limited ability to furnish health information and they update public mostly on the health services. ${ }^{\text {vii }}$ In an attempt to overcome this and to broaden the horizon of health news reporting, the National Health Education Information and Communication Centre (NHEICC), the responsible government body under the Ministry of Health and Population (MoHP), has a program to organize interaction sessions for local journalists across 75 
districts every year along with updating them on health related facts and figures. ${ }^{\text {ix }}$ In addition, the Nepal Health Research Council (NHRC), another body of MoHP, and few nongovernmental organizations i.e., Nepal Press Institute, Health Journalism Association of Nepal (HEJAN) and National Media Development Center also provide periodic skills enhancement trainings occasionally to journalist residing in Nepal including the rural areas to increase health coverage in newspaper and improving its quality. However, thoguth there is access of news sources to Kathmandu-based journalists to collect information from government organizations, due to lack of adequate knowledge about health reporting they are not effectively covering health related stories in the newspapers.

\section{Health News Clipping Project}

The Nepal Family Health Program II (NFHP II), funded by the United States Agency for International Development (USAID) and implemented between 2007 and 2012, attempted to learn about media roles in health awareness and advocacy for quality services. Thus, it partnered with HEJAN to implement the Health News Clipping Project between 2009 and 2011 for 28 months. The project aimed to record the daily and weekly health reporting published in eighteen selected newspapers so as to identify the actual position of the health reporting coverage, to identify gaps and to contribute in improving quality and quantity of the health reporting.

The purpose of this paper is to provide a snapshot of the health reporting that were published in selected newspapers. It includes discussion on the range of health topics, based on the 42 predefined keywords, placement of health reporting and space given, report type and the coverage by development region. The paper also intends to analyze the key issue of the sample of the health reporting. 


\section{Methodology}

This article has used the data of the Health News Clipping Project. The project scanned any items related to health over 28 months from the 11 daily newspapers (seven Nepali and four English) and seven weekly newspapers (five Nepali and two English) and entered information on publication name, type, date and page, administrative region and district from where the news was covered, reporting type and 42 pre-determined key words covering different dimensions of health in the reporting itself into a database. Every reporting was provided a unique identification, scanned and stored in digital format. The quality of data was monitored by a senior project staff on weekly basis. These newspapers were pre-identified by NFHP II and HEJAN based on their high circulation volume and for their being published from the urban centers.

The project captured 5,968 health related news stories. Each reporting had one or more keywords, which constituted a total of 26,514 keywords. Analysis was done by the primary keyword for each story as well as the distribution of all 26,514 keywords to get a sense of the type of health topics or issues most frequently covered by the Nepali press. Doing separate content analysis of the 5,968 reporting would entail a huge task; therefore, for this article we randomly selected five percent (294 reporting item) coverage stories from the 11 daily newspapers proportionate to the total number of coverage published in the 28 months time period. Weeklies were not included in the content analysis as they were less than one percent.

\section{Results}

\section{Newspapers' Health Reporting}

Out of the 5,968 health news stories captured by the project, the greatest coverage of health news was by Gorkhapatra (17\%), the oldest state-owned daily in Nepal. Kantipur and Annapurna 
Post, private dailies, stand second and third in the list by contributing 16 percent and 15 percent of the total health reporting.

Table 1 Health reports covered by different newspapers

\begin{tabular}{lrr}
\hline \multicolumn{1}{c}{ Name of Newspapers } & Number & \multicolumn{1}{c}{ Percent } \\
\hline Gorkhapatra & 1,025 & 17.2 \\
Kantipur & 931 & 15.6 \\
Annapurna Post & 870 & 14.6 \\
Rajdhani Dainik & 576 & 9.7 \\
The Himalayan Times & 496 & 8.3 \\
Samachar Patra & 492 & 8.2 \\
The Rising Nepal & 441 & 7.4 \\
Naya Patrika & 367 & 6.1 \\
Nagarik & 309 & 5.2 \\
The Kathmandu Post & 270 & 4.5 \\
Republica & 132 & 2.2 \\
Nepali/English weekly & 59 & 1.0 \\
\hline Total & $\mathbf{5 , 9 6 8}$ & $\mathbf{1 0 0 . 0}$ \\
\hline
\end{tabular}

These three dailies covered close to half of all health news in the time period. All other newspapers contributed less than 10 percent, individually, to the total health reporting. The stateowned English daily, The Rising Nepal, contributed to 7 percent of the total health coverage. The contribution of all the weekly newspapers combined in publishing health reporting was nominal i.e., one percent (Table 1). Almost all the health coverage was captured from the daily newspapers and more than three-fifths $(63 \%)$ were from national vernaculars.

\section{Health Reporting Placement}

The placement of the health reporting, whether in first or other pages is related to readership and perceived importance of the coverage items. The majority $(83 \%)$ of the health coverage captured by the project was published in inside pages of the newspapers, which is considered as having fewer readers and conveys less importance, and their proportions ranged from 72 percent in English daily newspapers to 87 percent in Nepali daily newspapers. Overall, one out of 10 health coverages was 
Figure 1 Health Reporting Placement (Page-wise)

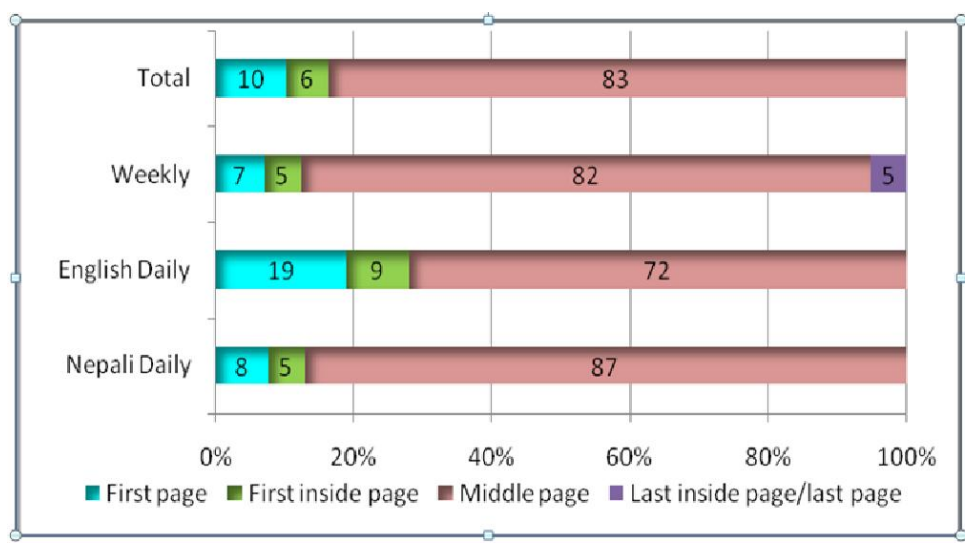

published on the first page. The English dailies ranked first in first page placement of the reporting compared to Nepali dailies and the weeklies. Six percent of the total health news was published in the first inside page of the newspapers. Five percent of the health coverage published in weekly newspapers was on the last page while neither Nepali daily nor weekly papers published it there.

\section{Health Reporting by Category}

The project grouped health reporting as "News" if it consisted of reports of events, "Columns" if it presented opinion by writers who can be syndicated regular contributors, one-time contributors, or newspaper staff members, "Feature Story" if it was a article on a particular topic, or "Editorial" if it expressed opinions on various subjects.' $x$ The majority $(86 \%)$ of the health reporting published in the newspapers was news, six percent columns, five percent feature stories, two percent editorials and remaining one percent were promotions, announcements, and interviews. 


\section{Health Coverage based on Geographical Regions}

The health coverage published in the newspapers was related to different geographical areas of Nepal. Overall, slightly more than one-third (35\%) of the health reporting presented national level health issues. Reports from the Central development region were 18 percent, highest among the five development regions and reporting from the Far-western development region was only seven percent, indicating least health reporting in the Far-west among the five development regions (Figure 2).

Figure 2 Health Reporting by Development Regions

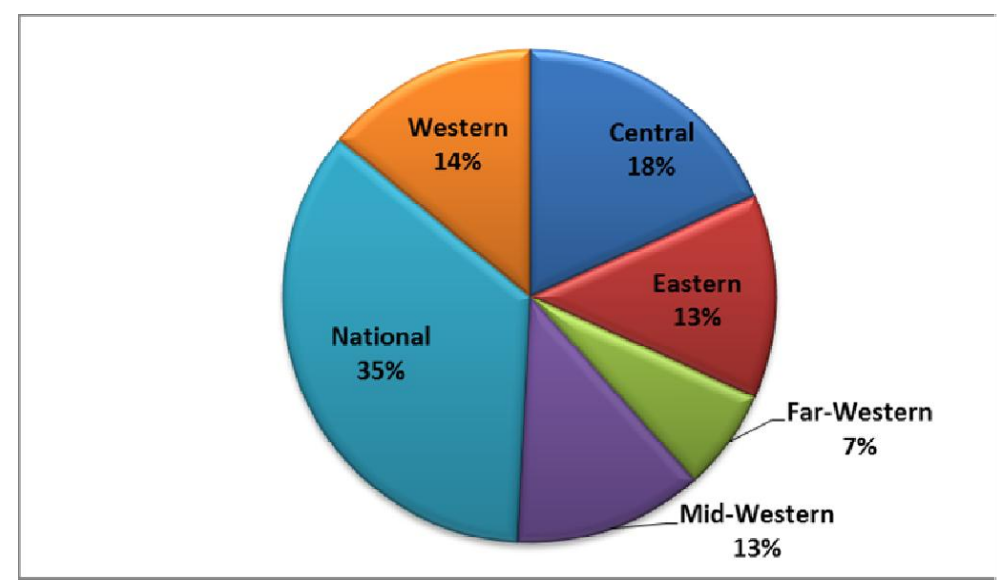

As most of the monitored newspapers are published from Kathmandu, they are more likely to report on health related national issues and the issues surrounding the central region.

Health Reporting by Key Words

Forty-two key words ${ }^{1}$ were identified as basis for the inclusion of the reporting in the database and the health news items were

1. health facility, 2. Ministry of Health and Population/Department of Health Services (MoHP/DoHS), 3. DPHO/DHO, 4. health worker, 5. epidemic outbreak, 6. drug and medical supply, 7. NGO/INGOs, 8. funding 9. 
scanned to see which coverage included how many of the key words. If a health reporting contained more than one key word, all of them were recorded. Similarly, if a key word appeared more than once in a health reporting it was recorded only once. Figure 3 presents the ten most commonly used key words in health reporting. Of the total reports, three-fifths (62\%) mentioned 'Health Facility' at least once, therefore, ranked as the most frequently used key word. Nearly one-half of the reports mentioned 'Health Worker' and 'MoHP/DoHS', while 40 percent of the clips mentioned 'DPHO/DHO'. These three most frequently cited key words possibly imply that the news report relates to service delivery or operational issues. Other key words that were listed in the top ten includes drug and medical supplies, epidemic, maternal and neonatal health $(\mathrm{MNH})$, quality issues, funding, and NGO/INGOs. The five least mentioned (Less than 2\%) key words included community and home-based care, girls trafficking, malnutrition, early marriage and vitamin A, thereby implying that these important health issues have not captured the attention of journalists.

Overall, nearly three-quarters (73\%) of all the reporting contained 2-6 key words, 16 percent contained 7-10 key words, nine percent contained only one key word and two percent contained more than 10 key words. Four stories did not have any of the pre-identified key words but were related to health information, so was included in the database. The average number of key words covered by the reporting was 4.4 .

policy, 10. staffing, 11. maternal and neonatal health, 12. quality problem, 13. HIV/AIDS, 14. study/research, 15. private health services, 16. health financing, 17. labor action, 18. special day/campaign, 19. equipment, 20. influenza, 21. politicians/MPS speech, 22. building, 23. sexually transmitted infection, 24. child illness, 25. commercial sex worker, 26. voluntary counseling and testing, 27. immunization, 28. intravenous drug users, 29. health training, 30. anti-retro viral treatment, 31. district AIDS coordination committee, 32. family planning, 33. labor migration, 34. natural disaster, 35. condom, 36. girls trafficking, 37. female community health volunteers 38 . community and home based care, 39. malnutrition, 40. early marriage, 41.vitamin A, and 42. public private partnership. 
Figure 3 Most Used Key Words

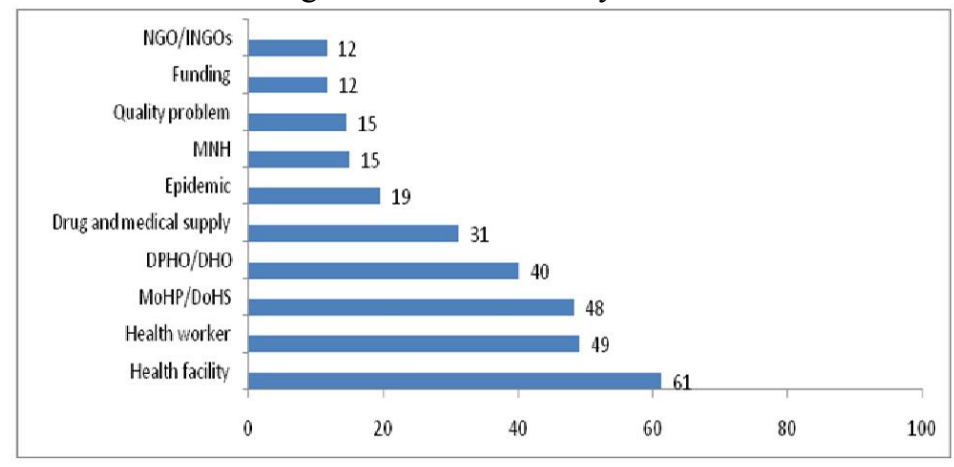

\section{Content Analysis of Health Reporting}

The purpose of content analysis of the sample health reporting was to understand the type of issues that are reported commonly by the Nepali press. The content analysis of the 294 health coverage found domination of three issues - i) communicable diseases, ii) health system, and iii) governance as the primary ones in the reporting. These 3 topics constitute over half of all news stories. Nineteen percent of the sample coverage revolved around information related to different types of communicable disease and vector borne diseases including diarrhea, cholera, fever, pneumonia, swine and bird flu, malaria and dengue, and TB and leprosy; 18 percent of the reporting were related to the country's health system, mainly unrevealing facts of drug shortage and service quality, policy issues and gaps, progress on MGDs, service expansions and management problems in the system. Seventeen percent of the sample coverage reported primarily on governance issues such as health facility closure, health worker absenteeism, corruption, misuse of authority, and lack of responsiveness, accountability and transparency within the system. 8-9 percent of the health coverage primarily focused on HIV/AIDS related issues and non-communicable diseases such as kidney disease and its transplant, life-style related diseases such as obesity, diabetes and snake-bites and rabies. Six percent of the reporting was on the contribution made by the non-government organizations, private institutions and 
community to the health sector. Similarly, 4 percent of the reporting was on agitations made by patients, administrative staff and health workers. Other issues such as natural disaster, Aayurveda services, abortion, early marriage and girls trafficking, uterus prolapsed, blood transfusion, nutrition and quality of nursing education was reported in less than two percent of the reporting. About nine percent of the reporting was related to miscellaneous health topics.

Table 2 Distribution of the sample health reports by the key issue

\begin{tabular}{lrr}
\hline \multicolumn{1}{c}{ Primary issue } & $\mathrm{N}$ & $\%$ \\
\hline Communicable disease & 55 & 18.7 \\
Health Policy, systems and & 52 & 17.6 \\
services & 49 & 16.6 \\
Governance & 24 & 8.1 \\
Non-communicable disease & 26 & 8.8 \\
HIV/AlDs & 18 & 6.1 \\
Non-government, private sector & & \\
in health & 13 & 4.4 \\
Agitation/protest & 5 & 1.7 \\
Natural disaster & 5 & 1.7 \\
Ayurveda & 4 & 1.3 \\
Uterus prolapse & 4 & 1.3 \\
Abortion & 4 & 1.3 \\
Social Issuel & 4 & 1.3 \\
Blood transfusion & 3 & 1.0 \\
Nutrition & 3 & 1.0 \\
Qualityof nursing education & 25 & 8.5 \\
Miscellaneous & 29 & 100 \\
Total & 4 & \\
\hline
\end{tabular}

\section{Discussion and Conclusions}

Health reporting in newspapers is one area of journalism that has not been researched extensively in Nepal. Because of lack of empirical studies, we cannot estimate what proportion of the total coverage is occupied by health in Nepali press. However, this article provides some information on the types and range of health issues covered by the 11 mostly circulated dailies and seven weeklies for a period of 28 months. The state-owned vernacular Gorkhapatra has highest reporting on health followed by Kantipur. Health coverage in English dailies is minimum as compared to Nepali dailies. 
It was expected that the 11 dailies in 28 months should have produced about 8,624 newspapers ( 1 month $=28$ days). That means these newspapers have to produce 5,909 health related texts with an average of 0.68 reporting in one publication, indicating less than one health reporting in each issue of these newspapers. This indicates the trend of low emphasis in coverage of health news by the Nepali newspapers. The placement of health coverage in the newspaper indicates the importance given to the report by the Nepali press and its intention to draw attention of most readers. However, very few of the health reports were published in the first page, which suggests that health issues are not the priority news. Moreover, most of the health news is covered for the national and the central regions with least focus on mid and far-western regions and these regions are also known for poor health status.

Some important key words appeared less frequently in the health news. Despite the important role of female community health volunteers (FCHVs) in improving health status of Nepalese, only two percent of the newspapers covered stories on them. Girls trafficking, labor migration, early marriage are some examples of the social issues that impact upon individual's and family's health. However, such issues were sporadically reported by the newspapers. A UK-based study reports that health news in newspapers is predominantly related to stories of service delivery and health scares (that are risks to public health) and themes on preventive health measures and major public health risks received little news coverage. ${ }^{\mathrm{xi}}$ Low reporting of key words such as Vitamin A, FCHV, and immunization in Nepali press also indicates similar practice of lower attention to health journalism in Nepal.

Much of the health news reporting has relied upon the personal skills of the journalists who seldom review the quality of the news once reported. Therefore, there is a need that the news reported by the journalists should be analyzed and interpreted along with providing suggestions for improving news quality. ${ }^{\text {ii }}$ Whilst the project did not specifically intend to assess the 
quality of reporting, but it gave an impression that very few of the health coverage could be rated as good quality. More indepth analysis of the quality of the health coverage is important.

This paper primarily used data from health news clipping project which was initiated with a limited purpose of just understanding the type of issues being published in the Nepali press. This evolution of the project became increasingly useful to the implementing agency in understanding the type of news covered. Several types of learning emerged during the study. For example, the project used key words to scan health coverage from newspapers and entered in database. For some reporting, the key words itself presents the issue of the report but for other the key words were not sufficient to disclose the primary issue of the reporting. Therefore, analysis of keywords alone did not allow a complete content analysis. Secondly, key words were limited to project selection, and some important words in the health sector were missed in the list of key words. This learning will be of value in designing of similar projects in future.

Monitoring of health news in print media is important as it can provide data on health issues covered in popular dailies and provide feedback on future topics to be covered to improve the health status of people by making them aware of health issues. It can also provide important feedback on governance issues related to health, either real or perceived. Moreover, it can bring attention to the responsible bodies on the pertinent health issues. It is also suggested that the MoHP take initiative in monitoring media in terms of health news publication, placement in the newspaper, their coverage and quality issues. 


\section{References}

Aditya, A. (ed.) (1996) Mass Media and Democratization: A Country Study of Nepal. Kathmandu:

Institute of Integrated Development Studies.

ii Gupta A. and Sinha, A.K. (2010). Health coverage in mass media: a content analysis. J Communication, 1(1): 19-25 (2010)

iii Cohen, B. (1963). The Press and Foreign Policy. Princeton, USA: Prienceton University Press.

iv Neuman, W.R., Just, M. R. and Crigler, A. N. (1992). Common knowledge-News and the Construction of Political Meaning, The University of Chicago Press.

$\checkmark$ Ministry of Health Population (MoHP) [Nepal], New ERA, and ICF International Inc. 2012. Nepal Demographic and Health Survey 2011. Kathmandu, Nepal: Ministry of Health and Population, New ERA, and ICF International, Calverton, Maryland.

vi Freimuth, V.S., Greenberg, R.H., DeWitt, J., Romano, R. (1984). Covering Cancer: Newspapers and the Public Interest. Journal of Communication, 34: 62-73.

Society for Local Integrated Development Nepal [SOLID] Nepal, Nepal Health Journalists Group [NEHAG] (2012). Workshop on meaningful participation of media for the prevention of early marriage and early pregnancy: workshop proceedings, 28th June 2012.

viii Health Journalist Association of Nepal (HEJAN) (2010). News Clipping Service. Kathmandu, Nepal: Health Journalist Association of Nepal.

ix National Health Education, Information and Communication Center (NHEICC). 2011. District level health education and communication program implementation booklet 2068/69. Ministry of Health and Population [MoHP], Kathmandu, Nepal.

$\mathrm{x}$ A Daily Miracle: A student guide to journalism and the newspaper business.

http://www.nieworld.com/cc/NewspaperADailyMiracle.pdf. Retrieved on September 7, 2012.

xi Harrabin R, Coote A, Allen J. (2003). Health in the news: Risk, reporting and media influence. King's Fund Publications. www.kingsfund.org.uk/summaries. 2003. 
xii British Broadcasting Cooperation (BBC) (2012). Sajha Sawal Episode 250: Role of Media in shaping agendas http://bbcsajhasawal.com/newsite/np/video/35/nepali-media/ Retrieved on 7 September 2012.

The authors are associated with Nepal Family Health Program II funded by the United States Agency for International Development (USAID) and Health Journalists Association of Nepal, Babarmahal. 